\title{
PERBEDAAN EFEKTIVITAS MUROTTAL AL-QURAN DAN TERAPI AKUPRESUR TERHADAP NYERI HAID PADA REMAJA PUTRI KELAS X DI SMAN 2 UNGARAN KABUPATEN SEMARANG
}

\author{
Masruroh $^{1}$, Heni Setyowati ${ }^{2}$ \\ vinamasruroh@yahoo.co.id \\ h3nysetyo@yahoo.co.id \\ Fakultas ilmu kesehatan,Prodi DIV Kebidanan \\ Universitas ngudi waluyo Semarang
}

\begin{abstract}
Abstrak
Nyeri haid adalah aliran menstruasi yang sulit atau menstruasi yang mengalami nyeri diperut bagian bawah dan biasanya disertai mual, pusing, bahkan pingsan yang dapat menggangu aktivitas belajar siswi.Metode untuk mengurangi nyeri haid dengan terapi non farmakologi yaitu dengan Murottal Al-Quran dan terapi Akupresur .Tujuan penelitian untuk mengetahui efektifitas dan perbedaan nyeri haid sebelum dan sesudah diberikan Murottal Al -Quran dan terapi Akupresur

Metode penelitian yang digunakan adalahpre eksperimental dengan pendekatan studi true experimental rancangan pre-post test. Metode pengumpulan data dengan kuesioner, analisis bivariat dengan uji wilcoxcon math paired dan man withney $u$ test.Populasi penelitian ini adalah seluruh semua siswi kelas x di SMAN 2 Ungaran sebanyak 243 siswi .Teknik pengambilan sampel dengan Purposive sampling sebanyak 40 siswi

Hasil penelitian menunjukkan bahwa ada perbedaan yang signifikan sebelum dan sesudah dilakukan terapi Murottal Al-Quranp value 0,0001< a $(0,05)$ dan terapi Akupressur p value 0,000 $<$ a $(0,05)$. Terapi Murottal Al-Quran dan terapi Akupressur ada perbedaan yang signifikan dalam pengurangan nyeri haid pada siswi kelas X di SMAN 2 Ungaran .

Ada perbedaan yang signifikan antara Murottal Al-Quran dan Akupresur terhadap nyeri haid yang dirasakan oleh siswi kelas X di SMA 2 Ungaran. Metode murottal al quran lebih efektif dalam mengurangi nyeri haid pada siswi kelas X di SMAN 2 Ungaran. Quran .

Diharapkansiswi yang mengalami nyeri haid dapat diatasi dengan metode Murottal Al
\end{abstract}

Kata Kunci : Efektivitas, Murottal Al-Quran, Terapi Akupressur, Nyeri Haid

\section{Pendahuluan}

Menstruasi yang terjadi pada saat pertama kali merupakan pertanda seorang remaja sedang mengalami pubertas.Peningkatan hormon menyebabkan beberapa perubahan fisik pada remaja putri, yaitu pematangan payudara, ovarium, rahim dan vagina ${ }^{1)}$

Salah satu masalah dalam kesehatan reproduksi remaja adalah disminore yang sering terjadi pada remaja ketika menstruasi. Disminore primer merupakan disminore yang mulai terasa sejak menarche dan tidak ditemukan kelainan dari alat kandungan atau organ lainnya. Disminore primer terjadi pada $90 \%$ wanita dan biasanya terasa setelah mereka menarche dan berlanjut hingga usia pertengahan 20an atau hingga mereka memiliki anak. Sekitar $10 \%$ penderita disminore primer tidak dapat mengikuti kegiatan seharihari. ${ }^{2)}$

Cara mengurangi disminore dapat dilakukan dengan 2 cara yaitu farmakologi dan non farmakologi. Terapi non farmakologi di kenal sebagai terapi yang lebih aman dari pada terapi faramakologi yang cenderung memiliki efek samping yang nantinya membahayakan. Terapi non faramakologi hadir sebagai terapi yang murah, mudah dan tidak membahayakan, salah satu terapi non farmakologi adalah terapi murrottal Al- 
Quran dan terpi akupresur yang mana terapi ini merupakan bentuk pengobatan yang irit biaya, bahkan tidak memerlukan biaya sedikitpun dan merupakan pengobatan tanpa efek samping dan bisa didapatkan setiap saat, dimanapun dan dalam keadan bagaimanapun $^{3)}$

Pengobatan

menggunakan

lantunan Al-Quran di dasarkan pada suara yang masuk melalui telinga akan berjalan melalu saraf pendengaran dengan panduan selaput pendengar dan di respon oleh setiap sel dalam anggota tubuh. Suara inilah yang dapat mengubah peyimpanan getaran sel yang menyebabkan sakit sehingga dapat bereaksi menyembuhkan ${ }^{3)}$

Penelitian yang dilakukan oleh Westri Prastiwi pada tahun 2017 dengan judul "Pengaruh Alunan Murottal Terhadap Intensitas Nyeri Dismenore Primer pada Siswi Aliyyah di Pondok Pesantren As Salafiyyah Mlangi Yogyakarta" di dapatkan hasil bahwa dari 30 responden 9 orang responden $(30 \%)$ mengalami nyeri ringan, 16 orang responden $(53,3 \%)$ mengalami nyeri sedang dan 5 orang responden $(16,7 \%)$ mengalami nyeri berat. Analisis data menggunakan Parametric Test dengan uji paired TTest dengan hasil uji statistik p $(0,000)$ $<\alpha(0,05)$ yang mana dapat disimpulkan bahwa murottal dapat menurunkan tingkat disminore pada siswi Aliyyah di Pondok Pesantren As Salafiyyah Mlangi.

Berdasarkan data profil kesehatan Indonesia tahun 2016 angka dismenore sebesar $64,25 \%$ yang terdiri dari $54,89 \%$ dismenore primer dan 9,36\% dismenore sekunder. Biasanya gejala dismenore primer terjadi pada wanita usia produktif 1-5 tahun setelah mengalami haid pertama dan wanita yang belum pernah hamil. Angka dismenoredi Jawa Tengah pada remaja diperkirakan mencapai 56\%. Berdasarkan data Dinas Kesehatan Kabupaten Semarang 2013 wanita usia 12-19 tahun yang mengalami dismenore jumlahnya yaitu $50-80 \%$, dan cakupan ini masih terbilang tinggi. ${ }^{4)}$

Berdasarkan hasil penelitian yang dilakukan Seung-Hun Cho (2016), dimana hasil nya Empat RCT terdiri dari total 458 peserta sistematis. Hanya satu dari percobaan termasuk dijelaskan metode yang memadai pengacakan. Akupresur dapat mengurangi rasa sakit dan kecemasan khas dismenorea dalam studi Taiwan. Penelitian AS dengan menggunakan perangkat akupresur melaporkan bahwa pengurangan nyeri haid secara signifikan lebih baik dalam nyeri haid terburuk yang pernah dialami oleh peserta, data yang tersedia dari RCT menunjukkan bahwa akupresur dapat meredakan nyeri haid. ${ }^{5)}$

Berdasarkan studi pendahuluann yang dilakukan oleh peneliti di SMA 2 Ungaran di dapatkan hasil bahwa dari 20 responden 7 orang remaja mengalami nyeri ringan, 10 orang remaja mengalami nyeri sedang, 3 orang remaja mengalami nyeri berat dan 2 orang remaja yang mengalami nyeri berat merasakan sakit yang sangat menggangu hingga menyebabkan pelajar pernah izin pada saat pembelajaran. Dari hasil wawancara kepada 20 remaja putri di SMA 2 Ungaran terdapat berbagai macam cara untuk mengatasi keluhan nyeri disminore seperti, makan, berbaring, dibiarkan saja, minum obat pereda nyeri dan lain-lain, untuk terapi Murrotal Al Quran dan Terapi Akupresur remaja putri belum mengetahui.

Berdasarkan latar belakang diatas maka peneliti tertarik untuk mengetahui "Perbedaan Efektifitas Murrotal AlQuran dan terapi Akupresur Terhadap Nyeri Haid pada siswi kelas $\mathrm{X}$ di SMAN 2 Ungran Kabupaten Semarang "

\section{Metode Penelitian}

Jenis penelitian yang digunakan adalahpre eksperimental dengan pendekatan studi true experimental rancangan pre-post test dengan pendekatan secara cross 
sectional.Metode pengumpuan data dengan kuesioner, analisis univariat dengan distribusi frekuensi dan analisis bivariat dengan ujiwilcoxcon math paired dan man withney u test.Populasi dalam penelitian ini adalah seluruh siswi kelas $\mathrm{X}$ di SMAN 2 Ungaran berjumlah 243 siswi. Sampel dalam penelitian ini sebanyak 40 siswi yang terdiri 20 siswi kelompok Murrotal Al Quran dan 20 siswi kelompok terapi Akupresur. Teknik dalam pengambilan sampel dalam penelitian ini adalah purposive sampling

\section{Hasil dan Pembahasan}

a. Hasil Penelitian

Tabel 2.1 Tingkat nyeri haid sebelum dan sesudah diberikan terapi Murottal Al Quran pada siswi kelas x di SMAN 2 Ungaran

\begin{tabular}{llc}
\hline $\begin{array}{l}\text { Tingkatan } \\
\text { Disminor }\end{array}$ & Sebelum & Sesudah \\
\hline $\begin{array}{l}\text { Tidak } \\
\text { nyeri }\end{array}$ & 0 & 0 \\
$\begin{array}{l}\text { Nyeri } \\
\text { ringan }\end{array}$ & 0 & $17(85 \%)$ \\
$\begin{array}{l}\text { Nyeri } \\
\text { sedang }\end{array}$ & $17(85 \%)$ & $3(15 \%)$ \\
$\begin{array}{l}\text { Nyeri } \\
\text { berat } \\
\text { terkontrol }\end{array}$ & $3(15 \%)$ & 0 \\
\hline Jumlah & $20(100 \%)$ & $20(100 \%$ \\
\hline
\end{tabular}

Hasil pada tabel diatas setelah diberikan diberikan terapi murottal AlQuran didapatkan hasil bahwa responden mengalami penurunan tingkat nyeri. Hal ini disebabkan karena setelah diberikan terapi murottal AlQuran responden mendapatkan efek relaksasi sehingga dapat mengalami penurunan tingkat nyeri haid yang dirasakan.

Kesimpulan yang serupa juga diungkapkan oleh para ilmuan sejak lama bahwa suara adalah getaran dan setiap sel pada tubuh manusia juga bergetar dengan getaran yang terbatas, gelombang suara bekerja memengaruhi sel-sel tubuh sehingga jika tubuh di hadapkan pada suara tertentu, suara itu akan memengaruhi keseimbangan gelombang di dalam tubuh dan memengaruhi bagian tubuh yang mendapat gangguan sehingga bagian tubuh akan merespon suara tersebut dengan getaran-getaran tertentu yang sinyalnya di kirimkan ke pusat sistem saraf yang mengatur seluruh tubuh. Dengan kata lain, suara yang diperdengarkan akan memicu sel-sel itu untuk merespon dan memperbaiki kerusakan sistemnya sehingga bisa dikembalikan pada kondisi sebelum rusak . ${ }^{6)}$

Tabel 2.2Tingkat nyeri haid sebelum dan sesudah diberikan terapi Akupresur pada siswi kelas X di SMAN 2 Ungaran

\begin{tabular}{|c|c|c|}
\hline $\begin{array}{l}\text { Tingkatan } \\
\text { Disminore }\end{array}$ & Sebelum & Sesudah \\
\hline $\begin{array}{l}\text { Tidak nyeri } \\
\text { Nyeri ringan } \\
\text { Nyeri } \\
\text { sedang } \\
\text { Nyeri berat } \\
\text { terkontrol }\end{array}$ & $\begin{array}{c}13(65 \%) \\
7(35 \%)\end{array}$ & $\begin{array}{l}0 \\
11(55 \%)\end{array}$ \\
\hline Jumlah & 20 & 20 \\
\hline
\end{tabular}

Berdasarkan Hasil pada tabel 2.2 dapat diketahui bahwa setelah diberi terapi Akupresur nyeri haid mengalami penurunan

Responden setelah diberikan terapi akupresur memiliki efek analgesik dengan cara merangsang serabut syaraf besar sehingga gerbang menjadi menyempit dan rangsangan pada sel $\mathrm{T}$ menjadi berkurang dan pada akhirnya nyeri haid akan diteruskan ke pusat nyeri sehingga nyeri menjadi berkurang.Hal ini menunjukkan bahwa tindakan akupresur efektif untuk menurunkan nyeri haid. Sesuai dengan teori Hartono (2012) yang menyatakan nyeri haid dapat dikontrol dengan memberikan rangsangan atau stimulus, yang salah satu stimulusnya yaitu dengan memberikan terapi akupresur ini, bahwa terapi akupresur ini dapat merangsang produksi endorphin lokal, dan selain itu terapi akupresur ini dapat 
menutup gerbang terhadap rangsang nyeri yaitu dengan mempertimbangkan tempat masase/penekanan dalam mengontrol nyeri haid. Seperti halnya pada remaja yang sedang nyeri haid seringkali daerah lumbosakral diurut dan dipijat yang mana tindakan ini akan merangsang mekanoreseptor sehingga nyeri menjadi berkurang, penekanan titik akupoin yang terletak pada daerah antara lumbal ke 4 dan 5 (meridian kandung kemih) selama 3 sampai 5 menit yang akan dapat memberikan kenyamanan di saat mengalami nyeri haid/ disminore. ${ }^{7)}$

Pada penelitian ini tedapat sebagian kecil dari responden dalam kategori mengalami nyeri sedang sejumlah 9 siswi ( $45,0 \%)$, dan beberapa tanda dan gejala yang dialami oleh responden seperti nyeri pada perut bagian bawah dan punggung, mual, dan rasa pusing yang tidak dapat dirasakan lagi oleh responden setelah diberikan terapi akupresur, hal ini juga sejalan dengan penelitian ynag dilakukan oleh Eni (2012), yang mengatakan bahwa remaja putri yang diberikan terapi akupresur pada titik acupoint selama 3 sampai dengan 5 menit maka akan lebih bebas dari nyeri yang dialami, karena terapi akupresur ini akan merangsang tubuh dan merangsang senyawa endorphin yang merupakan pereda nyeri yang alami dan menciptakan perasaan nyaman serta rileks pada tubuh patofisiologi nyeri haid biasanya terjadi pada saat fase pramenstruasi (sekresi) pada fase ini terjadi peningkatan hormon prolaktin dan hormon esterogen. ${ }^{8)}$

Sesuai dengan sifatnya, prolaktin dapat meningkatkan kontaksi uterus hormon yang juga terlibat dalam disminore adalah hormon prostaglandin. tujuan dari pengobatan nyeri haid dengan terapi akupresur adalah untuk menyeimbangkan hormon yang berlebihan karena pada dasarnya nyeri haid merupakan sakit yang berhubungandengan ketidakseimbangan hormon. Penyebab terjadinya nyeri haid dikarenakan adanya peningkatan produksi prostaglandin. Peningkatan ini akan mengakibatkan kontraksi uterus dan vasokonstriksi pembuluh darah, aliran darah yang menuju ke uterus menurun sehingga uterus tidak mendapat suplai oksigen yang adekuat sehingga menyebabkan nyeri. Terapi akupresur secara empiris terbukti dapat membantu meningkatkan hormon endorphin otak yang secara alami dapat membantu menawarkan rasa nyeri saat haid. Intensitas nyeri berbeda karena dipengaruhi oleh deskripsi individu tentang nyeri, persepsi dan pengalaman nyeri. ${ }^{7}$

Tabel 2.3 Perbedaan nyeri haid sebelum dan sesudah dilakukan terapi Murottal Al-Quran pada siswi kelas X di SMAN 2 Ungaran

\begin{tabular}{|l|l|l|l|l|l|}
\hline Variabel & Perlakuan & $\mathrm{N}$ & Mean & $\mathrm{Z}$ & $\begin{array}{l}\mathrm{p}- \\
\text { valu } \\
\mathrm{e}\end{array}$ \\
\hline $\begin{array}{l}\text { Nyeri } \\
\text { haid }\end{array}$ & Sebelum & 20 & 10.50 & -4.472 & $\begin{array}{l}0.00 \\
0\end{array}$ \\
\hline & Sesudah & 20 & 0.00 & & \\
\hline
\end{tabular}

Berdasarkan hasil penelitian menunjukkan bahwa rata-rata skala tingkat nyeri haid sebelum dilakukan tindakan terapi murottal Al-Quran sebesar 10.50 kemudian berkurang menjadi 0.00 sesudah dilakukan tindakan murottal Al-Quran.

Berbagai macam pengobatan mulai berkembang seiringnya zaman, salah satunya adalah terapi alternatif yang dikenal dengan nama sound healing. Sound healing menggunakan metode terapi lantunan Al-Quran menjadi salah satu alternatif yang di pilih untuk penyembuhan, termasuk diantaranya penyembuhan disminore yang sering di derita remaja. Prinsip yang digunakan untuk penyembuhan disminore sama seperti penyembuhan penyakit lainnya yang menggunakan terapi lantunan AlQuran. Remaja yang mengalami disminore akan di minta untuk 
mendengarkan lantunan ayat suci AlQuran sehingga suara akan ditangkap oleh telinga kemudian sel-sel di dalam tubuh akan merespon getaran suara tersebut terutama bagian tubuh yang mengalami kelainan sehingga bagian yang sakit akan kembali pada kondisi yang normal. ${ }^{3)}$

Pengaruh alunan murottal Al-Quran telah berhasil dilakukan untuk menurunkan nyeri yang terjadi. Hal ini mendukung penelitian yang pernah dilakukan oleh Heny Siswanti dan Ummi Kulsim tahun 2016 yang pernah melakukan penelitian untuk menurunkan nyeri pada pasien section caesare yang mana pemberian murottal Al-Quran dapat menurunkan nyeri yang dirasakan oleh respondennya yang berjumlah 20 responden, tidak hanya menurunkan nyeri, alunan murottal telah terbukti menenangkan dan menurunkan kecemasan pada ibu hamil dalam menghadapi persalinanya ${ }^{9)}$

Hasil penelitian yang dilakukan oleh Enggal dengan judul Murrotal AlQuran Therapy To Increase Sleep Quality In Nursing Students terbukti bahwa bahwa murottal Al-Quran sangat efektif untuk meningkatkan kualitas tidur, dimana 8 dari 20 siswa mengalami gangguan tidur pada saat disminore. ${ }^{10)}$

Tabel 2.4 Perbedaan nyeri haid sebelum dan sesudah dilakukan terapi Akupressur pada Siswi kelas X di SMAN 2 Ungaran

\begin{tabular}{|l|l|l|l|l|l|}
\hline Variabel & Perlakuan & $\mathrm{N}$ & Mean & $\mathrm{Z}$ & $\begin{array}{l}\text { p- } \\
\text { valu } \\
\text { e }\end{array}$ \\
\hline $\begin{array}{l}\text { Nyeri } \\
\text { haid }\end{array}$ & Sebelum & 20 & 5,95 & $-3,956$ & $\begin{array}{l}0.00 \\
0\end{array}$ \\
\hline & Sesudah & 20 & 0.55 & & \\
\hline
\end{tabular}

Berdasarkan hasil penelitian didapatkan hasil bahwa nilai $\mathrm{p}$-value $0,0001<\mathrm{a}$ $(0,05)$ terapi akupressur efektif dan mampu menurunkan nyeri haid pada siswi kelas $x$ di SMAN 2 Ungaran

Penurunan intensitas nyeri haid yang dialami oleh responden setelah diberikan terapi akupresur memiliki efek analgesik dengan cara merangsang serabut syaraf besar sehingga gerbang menjadi menyempit dan rangsangan pada sel $\mathrm{T}$ menjadi berkurang dan pada akhirnya nyeri haid akan diteruskan ke pusat nyeri sehingga nyeri menjadi berkurang. Selain itu, menurut teori endorphin, terapi akupresur ini dapat meningkatkan kadar endorphin yang ada didalam tubuh sehingga nyeri yang dirasakan menjadi berkurang

Temuan penelitian lain yang mendukung penelitian tentang efek terapi akupresur terhadap dismenore adalah penelitian yang dilakukan oleh Hasanah (2010). Penelitian tersebut dilakukan pada 54 responden yang mengalami dismenore primer dengan melakukan penekanan pada titik LR3 (taichong) pada fase lutheal. Hasil akhir menunjukkan bahwa responden mengalami penurunan intensitas nyeri yang signifikan dibandingkan dengan kelompok yang tidak dilakukan terapi akupresur, dengan kata lain secara signifikan bahwa akupresur dapat menurunkan rata-rata intensitas nyeri sebesar 1.037 poin $(\mathrm{p}$ value $=0,001) .{ }^{11)}$

Penelitian yang dilakukan oleh Nam Hyun Cha tahun 2016 menunjukan hasil yaitu Terapi akupresur Auricularis adalah intervensi yang efektif untuk mengurangi sakit perut, nyeri punggung, dan dismenore primer siswa SMA perempuan di Korea Selatan. Untuk kelayakan acupresur yakni terapi auricular, diperlukan untuk melatih dan mempelajari posisi yang tepat dari titik akupresur. Relevansi klinis: Pelayanan kesehatan harus mempertimbangkan untuk memberikan terapi akupresur auricular sebagai metode yang alternatif untuk mengurangi perut dan sakit punggung, dan dismenore primer pada siswa SMA perempuan di Korea Selatan. ${ }^{12)}$ menekan pada titik-titik tertentu (yang dikenal dengan nama acupoint) 
untuk menstimulasi aliran energy pada titik meridian. Daerah atau lokasi yang dilakukan penekanan ini disebut juga dengan acupoint.Acupoint terletak

Tabel 2.5 Hasil Uji T-test Sesudah di berikan Murrotal Al-Quran dan Akupresur terhadap nyeri haid pada remaja putri kelas $\mathrm{X}$ di SMAN 2 Ungaran Kab. Semarang

\begin{tabular}{|l|l|l|l|l|}
\hline & N & Mean & $\begin{array}{l}\text { Std } \\
\text { Deviation }\end{array}$ & P.value \\
\hline $\begin{array}{l}\text { Murottal } \\
\text { Al-Quran }\end{array}$ & 20 & 3,35 & 1,182 & 0,012 \\
\hline Akupresur & 20 & 2,80 & 1,542 & \\
\hline
\end{tabular}

Hasil perhitungan statistik menggunakan uji T-test Independent Sampel test di peroleh $\mathrm{p}$ value sebesar $0,012<\alpha(0,05)$ yang menunjukkan ada perbedaan yang signifikan terhadap kedua perlakuan baik murottal AlQuran maupun Akupresur terhadap nyeri haid yang dirasakan oleh remaja putri kelas $\mathrm{X}$ di SMA 2 Ungaran. Perubahan intensitas nyeri haid pada kelompok murottal Al-Quran Std Deviation sebesar 1,182 sedangkan pada kelompok Akupresur Std Deviation sebesar 1.542. Sehingga dapat disimpulkan bahwa murottal Al-Quran lebih efektif dari pada Akupresur dalam mengurangi nyeri haid pada remaja putri kelas X di SMA 2 Ungaran.

Murottal Al-Quran adalah rekaman suara Al-Quran yang dilagukan seorang qor'i atau qoria'ah. Lantunan Al-Quran secara fisik mengandung unsur manusia, sedangkan suara manusia mengandung instrument penyembuhan yang menakjubkan dan alat yang paling mudah di jangkau. Terapi Murottal AlQuran adalah cara yang paling mudah untuk mengembalikan keseimbangan sel-sel yang sakit, selain itu ia juga merupakan penyembuhan menyeluruh dan program sempurna bagi kesehatan hidup, tubuh, dan jiwa. ${ }^{3)}$

Kesimpulan yang serupa juga diungkapkan oleh para ilmuan sejak lama bahwa suara adalah getaran dan setiap sel pada tubuh manusia juga bergetar dengan getaran yang terbatas, gelombang suara bekerja memengaruhi sel-sel tubuh sehingga jika tubuh di hadapkan pada suara tertentu, suara itu akan memengaruhi keseimbangan gelombang di dalam tubuh dan memengaruhi bagian tubuh yang mendapat gangguan sehingga bagian tubuh akan merespon suara tersebut dengan getaran-getaran tertentu yang sinyalnya di kirimkan ke pusat sistem saraf yang mengatur seluruh tubuh. Dengan kata lain, suara yang diperdengarkan akan memicu sel-sel itu untuk merespon dan memperbaiki kerusakan sistemnya sehingga bisa dikembalikan pada kondisi sebelum rusak. ${ }^{13)}$

Nyeri haid yang terjadi pada remaja putri kelas $\mathrm{X}$ setelah diberikan terapi murottal Al-Quran tingkat nyeri berubah menjadi kategori ringan dan sedang. Pada penelitian remaja diminta untuk mendengarkan murottal AlQuran selama 15 menit dengan cara tidur dengan posisi miring ke kanan, hal ini disebabkan bahwa posisi miring cukup efektif untuk menghilangkan kram pada perut yang dirasakan pada saat nyeri menstruasi, posisi ini dianggap cukup membuat wanita merasa lebih rileks dan nyaman. Posisi miring ke kanan juga bisa mengurangi rasa tegang pada punggung. ${ }^{14)}$

Pengaruh alunan murottal Al-Quran telah berhasil dilakukan untuk menurunkan nyeri yang terjadi. Hal ini mendukung penelitian yang pernah dilakukan oleh Heny Siswanti dan Ummi Kulsim tahun 2016 yang pernah melakukan penelitian untuk menurunkan nyeri pada pasien section caesare yang mana pemberian murottal Al-Quran dapat menurunkan nyeri yang dirasakan oleh respondennya yang berjumlah 20 responden, tidak hanya menurunkan nyeri, alunan murottal telah terbukti menenangkan dan menurunkan kecemasan pada ibu hamil dalam menghadapi persalinanya. ${ }^{9)}$

Penelitian yang dilakukan oleh Magda Bhinnety (2008) menggunakan terapi murottal Al-Quran menunjukkan bahwa siswi yang membaca dan 
mendengarkan murottal Al-Quran memiliki daya ingat yang lebih baik dibandingkan dengan rekan-rekannya yang lain. Hal ini dikarenakan adanya pengaruh terhadap kemampuan ingatan jangka pendek terhadap perubahan gelombang otak. Selain itu juga terbukti bahwa membaca dan mendengarkan murottal Al-Quran dapat menurunkan kecemasan dan stress yang dihadapi di sekolah. ${ }^{15)}$

Akupresur atau yang biasa dikenal dengan terapi totok/ tusuk jari adalah salah satu bentuk fisioterapi dengan memberikan pemijatan dan stimulasi pada titik-titik tertentu pada tubuh. Terapi akupresur merupakan pengembangan diri ilmu akupuntur, sehingga pada prinsipnya metode terapi akupresur sama dengan akupuntur, yang membedakannya terapi akupresur tidak menggunakan jarum dalam proses pengobatannya. Akupresur berguna untuk mengurangi atau mengobati berbagai jenis penyakit dan nyeri serta mengurangi ketegangan dan kelelahan

Pada penelitian ini kedua peneliti melihat penurunan intensitas nyeri haid pada remaja putri kelas $\mathrm{X}$ di SMAN 2 Ungaran Kab.Semarang dengan membandingkan kelompok perlakuan murrotal Al-Quran dan kelompok perlakuan Terapi Akupresur.

\section{Kesimpulandan Saran}

a. Kesimpulan

1) Ada Perbedaan yang signifikan nyeri haid sebelum dan sesudah terapi Murottal Al Quran pada siswi kelas X di SMAN 2 Ungaran dengan $p$ value $0,000<\mathrm{a}(0,05)$

2) Ada Perbedaan yang signifikan nyeri haid sebelum dan sesudah terapi Akupresur pada siswi kelas $\mathrm{X}$ di SMAN 2 Ungaran dengan p-value 0,000 $<\mathrm{a}(0,05)$

3) Ada perbedaan yang signifikan antara terapi murottal Al-Quran dan Akupresur terhadap nyeri haid yang dirasakan oleh remaja putri kelas $\mathrm{X}$ di SMA 2 Ungaran dengan $\mathrm{p}$-value 0,012 $<\mathrm{a}(0,05)$

b. Saran

Dengan adaya penelitiaan ini, diharapkan para siswi dalam mengatasi nyeri haid yang dirasakan dapat mengunakan metode Murottal Al -Quran maupun Akupresur.

\section{Daftar Pustaka}

[1] Misaroh Siti \& Proverawati, Atikah. 2009. Menarche Menstruasi Pertama Penuh Makna. Yogyakarta : Nuha Medika.

[2] Nugroho, Taufan \& Utama, Bobby Indra. 2014. Masalah Kesehatan Reproduksi Wanita. Yogyakarta : Nuha Medika.

[3] Al-Kaheel, Abd Daim. 2012. Lantunan Qur'an Untuk Penyembuh. Yogyakarta : Pustaka Pesantren.

[4] Dinkes Kab.Semarang. 2016.Profil Dinas Kesehatan Kabupaten Semarang tahun 2016.

[5] Seung- Hun Cho,2016 Acupressure for primary dysmenorrhoea:A systematic review Journal Complementary Therapies in Medicine (2016) 18, 49-56.

[6] Westi Prastiwi. 2017. Pengaruh Alunan Murottal Terhadap Intensitas Nyeri Disminore Primer Pada Siswi Aliyyah Di Pondok Pesantren As-Salafiyah Mlangi Yogyakarta. http://digilib.unisayogya.ac.id/257 3/

[7] Hartono.2012. Akupresur untuk Berbagai Penyakit. Yogyakarta : Andi Offset.

[8] Eni Firda Julianti. 2012. Efektivitas Terapi Akupresur Terhadap Disminore Pada Remaja Di SMAN 5 dan MA Al-Huda 
Bengkalis Jurnal diterbitkan. :Universitas Riau.

[9] Heny Siswanti dan Ummi Kalsum.2016. pengaruh Terapi Murrotal Terhadap Nyeri Post Seksio Secaria Di Rsi Sunan Kudus Kabupaten Kudus Tahun 2016. Http:// 1194-145-3668-2-1020171113.pdf

[10] Enggal. 2017. Murrotal Al-Quran Therapy To Increase Sleep Quality In Nursing Students. https://jurnal.unej.ac.id/index.php/ prosiding/article/view/7189.

[11] Hasanah,Oswati.2010. Efektivitas Terapi Akupresur Terhadap Dismonire pada Remaja di SMPN 5 dan SMPN 13 Pekanbaru Jurnal diterbitkan. Depok :Universitas Indonesia.

[12] Nam Hyun Cha, PhD,2016 Effects of Auricular Acupressure Therapy on Primary Dysmenorrhea for Female High School Students in South Korea Journal of Nursing Scholarship, 2016; 48:5, 508-516

[13] Elzki, Jamal. 2014. Buku Saku Terapi Baca Al-Quran Mengerti Rahasia Kesehatan dalam Membaca dan Menyimak Kitab Suci. Jakarta : Zaman

[14] Magda. Bhinnety Etsem. 2011. The Effect Of Reciting Holy Quran Toward Short-Term Memori Ability Analysed Troght The
Changing

Brain

Wave.https://www.matec-

conferences.org/.../matecconf_icet $\underline{4 \mathrm{sd} 201}$

[15] Bekti Yuniyanti, Masini dan Haidayah.2014. Hubungan Tingkat Stres Dengan Tingkat Disminore Pada Siswi Kelas X dan XI SMK Bahkti Karyakota Magelang Tahun 2014. http://ejournal.poltekkessmg.ac.id/ojs/index.php/jurkeb/arti cle/view/119.

[16] Fengge, A.2012. Manfaat dan Teknik Pengobatan Terapi Akupresur. Yogyakarta Crop Circle Corp. 